\title{
Computational study of the effect of fuel element geometry on pellets' maximum temperature
}

\author{
Alexander Vorobiev $^{1, *}$, Ksenia Pavlova ${ }^{1}$ \\ ${ }^{1}$ National Research Tomsk Polytechnic University, 634050 Tomsk, Russia
}

\begin{abstract}
One of the factors that determine reliable operation of fuel elements in a nuclear reactor is maximum temperature of fuel pellets. This paper presents the computational study results of the effect of the pellet's central hole on its maximum temperature when using different types of fuel.
\end{abstract}

\section{Introduction}

Fuel elements are the most important and strained nodes in the core of a modern nuclear power plant reactor. The design of a fuel element must ensure its long-term operational reliability under extremely severe operating conditions.

At present most nuclear reactors are fueled with a compound known as uranium dioxide $\left(\mathrm{UO}_{2}\right)$, since this fuel does not interact with water and steam even at high temperatures, is compatible with fuel rod's cladding material, and is characterized by a high melting point. Among its downsides are low thermal conductivity and brittleness.

Uranium carbides ( $\mathrm{UC}$ and $\mathrm{UC}_{2}$ ) are seen as potential nuclear fuels. They are characterized by higher density as compared to $\mathrm{UO}_{2}$ and have a high thermal conductivity. The disadvantage of uranium carbides is a relatively high activity with many reactor materials. In the future the use of uranium nitrides (UN) and silicides is also possible. They are similarly characterized by high density and thermal conductivity but at the same time they are more compatible with reactor materials [1].

One of the most significant factors that determine operational reliability of a fuel element is maximum temperature of the fuel pellets. This temperature can be decreased by using fuel with higher thermal conductivity as well as by enhancing heat-transfer properties of a pallet-clad gas gap. Another method for lowering the peak temperature of the pellet involves application of fuel pellets with a central hole.

The objective of this work is to study the effect of a central hole and its dimensions on the pellets' maximum temperature when using different types of fuels.

\section{Calculations and methodology of the study}

* Corresponding author: worob@tpu.ru 
The model of the object of the computational study is given in Fig.1. The assumed geometry and mode characteristics of a conventional fuel element are presented in Table 1.

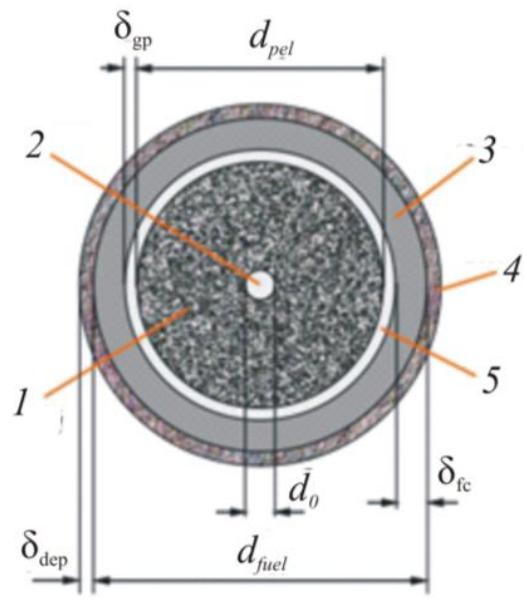

Fig 1. Cross-section of a conventional fuel rod: 1 - pellets; 2 - hole; 3 - cladding; 4 - deposits; 5 gap.

Table 1. Main characteristics of a conventional fuel element.

\begin{tabular}{|l|c|}
\hline \multicolumn{1}{|c|}{ Parameter } & Description \\
\hline Coolant & non-boiling water \\
\hline Gas in pellet-clad gap & helium \\
\hline Cladding material & $\mathrm{Zr}$ alloy \\
\hline Coolant pressure $p_{c}$ & $16 \mathrm{MPa}$ \\
\hline Coolant temperature $t_{c}$ & $305^{\circ} \mathrm{C}$ \\
\hline Coolant velocity $w_{c}$ & $6 \mathrm{~m} / \mathrm{s}$ \\
\hline Spacer arrangement & triangular \\
\hline Fuel rod pitch $S_{\text {pitch }}$ & 1.4 \\
\hline Pellet diameter $d_{\text {pel }}, \mathrm{mm}$ & $7.53 \mathrm{~mm}$ \\
\hline Cladding thickness $\delta_{c l}$ & $0.685 \mathrm{~mm}$ \\
\hline Gap thickness $\delta_{\text {gap }}$ & $0.1 \mathrm{~mm}$ \\
\hline
\end{tabular}

The algorithm for determining pellet's maximum temperature includes well-known expressions [2]. This algorithm suggests the use of different nuclear fuels; their thermal conductivity is calculated by means of approximating expressions [1, 4].

Temperature distribution in fuel pellets including peak temperature can be calculated in the process of solving one-dimensional heat conduction problem by Seidel iteration method [3].

To implement the algorithm mentioned above and perform calculations of the temperature characteristics of the fuel composition the FUEL computer program has been developed in the Department of Nuclear and Thermal Power Plants of the Tomsk Polytechnic University. The program is made in the Borland Turbo Delphi 2006 intergated development environment and is actually a Windows Service application. The program's executable module allows graphic interpretation of the calculation results and their import to MS Excel.

Screenshot of the FUEL program's main window is presented in Fig. 2. 


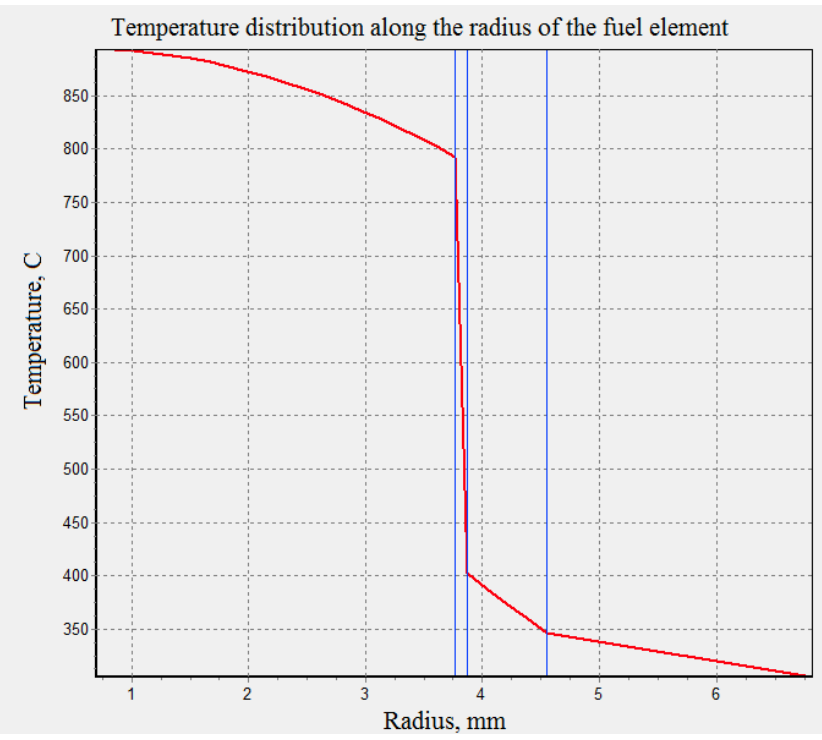

Fig. 2. Screenshot of the FUEL main window.

Two cycles of the variational calculations of the fuel rod's temperature characteristics were performed using the FUEL program (Fig.1). In each calculation cycle we varied the values for central hole diameter $\left(d_{0}=0 \ldots 2 \mathrm{~mm}\right)$ and fuel type $\left(\mathrm{UO}_{2}, \mathrm{UC}, \mathrm{UN}\right.$, and $\left.\mathrm{U}_{3} \mathrm{Si}_{2}\right)$.

The conditions for the first calculation cycle were: $q_{s}=$ const and $q_{l}=$ var (i.e. output of a fuel rod $N_{\text {fuel }}=$ var); for the second cycle: $q_{s}=\operatorname{var}$ and $q_{l}=\operatorname{const}\left(N_{\text {fuel }}=\right.$ const $)$.

The main calculation results for uranium dioxide are given in Fig. 3.

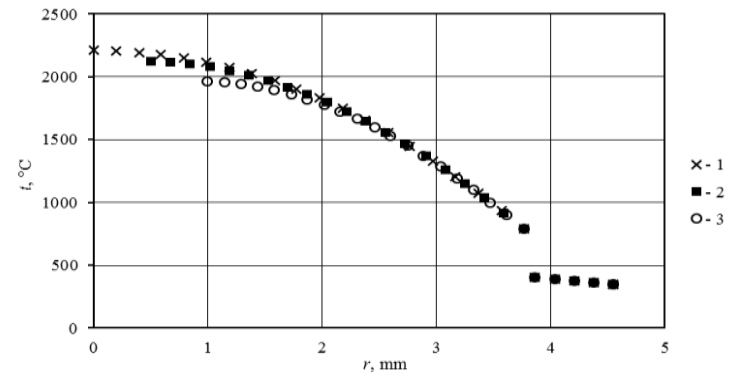

Fig. 3. Temperature distribution in a fuel rod (pellet material is $\mathrm{UO}_{2}$ ) at different diameters of the central hole. $q_{l}=440 \mathrm{Wt} / \mathrm{cm}: 1-d_{0}=0 ; 2-d_{0}=1 \mathrm{~mm} ; 3-d_{0}=2 \mathrm{~mm}$.

The main calculation results for other fuels are presented in Fig. 4. 


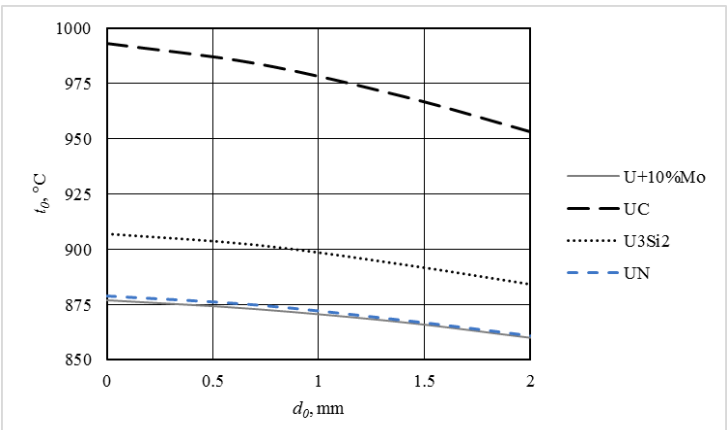

Fig. 4. Dependence of the pellets' maximum temperature on the diameter of a central hole for different fuels. $q_{l}=440 \mathrm{Wt} / \mathrm{cm}$.

\section{Conclusion}

1. The presence of a central hole in the fuel pellets decreases their maximum temperature $t_{0}$ for any of the common fuel types. Yet, the amount of the decrease in temperature is largely dependent on the type of fuel.

2. When changing the central hole diameter from 0 to $2 \mathrm{~mm}$ the most considerable decrease in $t_{0}$ is observed for the pellets made of uranium dioxide $\left(\sim 250^{\circ} \mathrm{C}\right)$. For other fuels changes in temperature $t_{0}$ are in the range of $17 \ldots 40{ }^{\circ} \mathrm{C}$, i.e. the decrease in temperature is much smaller.

3. Meanwhile, drop in the maximum temperature of the pellets due to the presence of a central hole is observed in both cases: when $q_{s}=$ const and when $q_{l}=$ const.

\section{References}

1. B.A. Kalin, Physical materials science: textbook (Izd. MEPhI, Moscow, 2008)

2. B.A. Dementiev, Nuclear power reactors: textbook. $2^{\text {nd }}$ edition (Energoatomizdat, Moscow, 1990)

3. N.M. Belyaev, A.A. Ryadno, Thermal conductivity theory methods: coursebook (Vysshaya shkola, Moscow, 1982)

4. P.L. Kirillov, Thermal physical properties of materials for nuclear equipment: reference book (Izdat, Moscow, 2007) 